\title{
Appendix: List of handshapes
}

In this section, we report the labels we adopted to refer to LIS handshapes. Notice that these conventions are followed in all the Parts of the grammar.

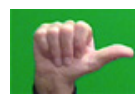

S

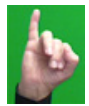

I

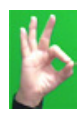

$\mathrm{F}$

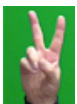

V

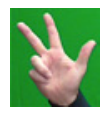

3

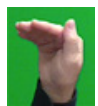

Flat open

4

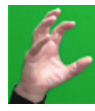

Spread

curved open 5

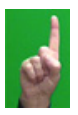

G

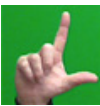

L

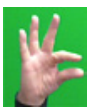

Flat open F

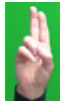

Unspread V

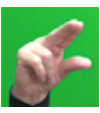

Flat open 3

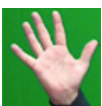

5

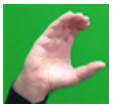

Unspread curved open 5

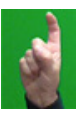

Curved open G

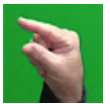

Flat open L

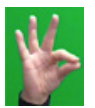

Flat closed F

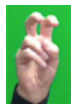

Curved open V

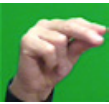

Flat closed 3

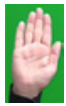

Unspread 5

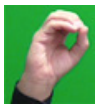

Curved closed 5

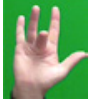

$3 / 5$
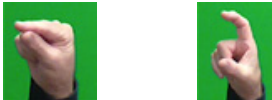

Flat closed L Curved open L
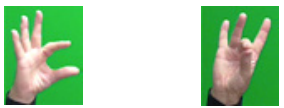

Curved open F 8
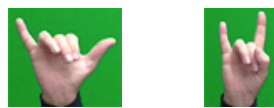

U
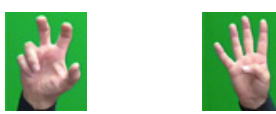

Cured open $3 \quad 4$
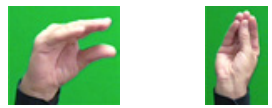

Flat open $5 \quad$ Flat closed 5 
